\title{
Patient awareness, perception and attitude to contrast-enhanced CT examination: Implications for communication and compliance with patients' preferences
}

\author{
Alena Lambertova ${ }^{1, A-C, E, F}$, Pavel Harsa ${ }^{1, A, E, F}$, Lukas Lambert ${ }^{2, A-D, F}$, Petr Kuchynka ${ }^{3, C, D, F}$, Jan Briza ${ }^{4, D-F}$, Andrea Burgetova ${ }^{2, D-F}$ \\ ${ }^{1}$ Department of Psychiatry, First Faculty of Medicine, Charles University and General University Hospital in Prague, Czech Republic \\ ${ }^{2}$ Department of Radiology, First Faculty of Medicine, Charles University and General University Hospital in Prague, Czech Republic \\ ${ }^{3} 2^{\text {nd }}$ Department of Medicine - Department of Cardiovascular Medicine, First Faculty of Medicine, Charles University and General University Hospital in Prague, Czech Republic \\ ${ }^{4}$ st Department of Surgery, First Faculty of Medicine, Charles University and General University Hospital in Prague, Czech Republic \\ A - research concept and design; $\mathrm{B}$ - collection and/or assembly of data; $\mathrm{C}$ - data analysis and interpretation; \\ $D$ - writing the article; $E$ - critical revision of the article; $F$ - final approval of the article
}

Address for correspondence

Lukas Lambert

E-mail:lambert.lukas@gmail.com

\section{Funding sources}

The study was funded by the Charles University in Prague (Progres Q28/LF1, UNCE 204065) and the Ministry of Health of the Czech Republic (RVO-VFN64165).

\section{Conflict of interest}

None declared

\section{Received on February 7, 2018}

Reviewed on March 9, 2018

Accepted on August 9, 2018

Published online on May 10, 2019

Cite as

Lambertova A, Harsa P, Lambert L, et al. Patient awareness, perception and attitude to contrast-enhanced CT examination: Implications for communication and compliance with patients' preferences. Adv Clin Exp Med. 2019;28(7):923-929. doi:10.17219/acem/94146

DOI

10.17219/acem/94146

\section{Copyright}

Copyright by Author(s)

This is an article distributed under the terms of the Creative Commons Attribution Non-Commercial License (http://creativecommons.org/licenses/by-nc-nd/4.0/)

\begin{abstract}
Background. Despite the high volume of contrast-enhanced computed tomography (CECT) examinations, there is limited awareness about its risks among patients and little is known about the influence of patient information sheets.
\end{abstract}

Objectives. The objective of this study was to assess patients' awareness and perception of risks related to CECT examination and how they are influenced by an information sheet.

Material and methods. A total of 263 adult patients scheduled for a CECT examination completed a questionnaire. The first page evaluated patients' characteristics, their fear and awareness about examinationrelated risks, and source of information. Page 2 contained the Zung self-rating anxiety scale. After reading the information sheet, patients completed page 3 that surveyed how their awareness and fear had changed.

Results. Nearly half of the patients underestimated the risk of secondary malignancy $(n=121,46 \%)$, or the risk of renal impairment $(n=110,42 \%)$. The vast majority $(n=227,86 \%)$ stated that they were not instructed to maintain fluid intake up to $1 \mathrm{~h}$ before the procedure. After reading the information sheet, patients generally corrected their knowledge, but 195 (74\%) reported experiencing greater fear ( $p<0.0001)$. Fear was more pronounced in younger female patients who had not undergone $C T$ previously. Patients feared the result more than examination-related risks. Most patients $(n=204,78 \%)$ would feel uncomfortable before receiving the examination result.

Conclusions. Most patients do not assess risks related to CECT examination correctly. Although the information sheet improves patients' understanding of (ECT-related risks, it lacks empathically delivered reassurance and increases their fear. Fast communication of examination results would make patients feel more comfortable.

Key words: multidetector computed tomography, radiation exposure, patient education, test anxiety scale, patient preference 


\section{Introduction}

Over the last decade, the utilization of cross-sectional imaging by computed tomography $(\mathrm{CT})$ has been increasing due to better availability, broader range of examinations, new treatments in oncology, and also medico-legal considerations. ${ }^{1,2}$ Concerns about radiation exposure to the population $^{3}$ resulted in numerous technical innovations in the $\mathrm{CT}$ industry aiming at reducing the radiation dose, while maintaining adequate diagnostic performance. ${ }^{4,5}$

However, little effort has been devoted to the assessment of patients' awareness, perception and attitude to radiation exposure during CT examination and its associated risks. ${ }^{3,6}$ Scarce data showed that not only patients but also medical professionals have limited insight into the amount of radiation delivered during diagnostic procedures and their debated effect on human health. ${ }^{3,7,8}$ Communicating the potential hazards associated with radiation exposure and contrast material administration, in addition to the uncertainty of the examination result, contribute to patients' fear. ${ }^{3,9}$

In this study, we assessed patients' evaluation of risks related to contrast-enhanced $\mathrm{CT}$ examination and the impact that informing the patient has on their awareness and fear of the examination.

\section{Methods}

This questionnaire study was performed in accordance with the Helsinki Declaration and approved by the local Institutional Review Board. Written informed consent was obtained from all participants.

The study was performed in a single tertiary university hospital from May to June 2017. A total of 315 adult patients consented to complete a questionnaire while waiting for a scheduled contrast-enhanced CT examination of the abdomen and pelvis \pm thorax. Patients with a physical or visual impairment preventing them from reading or completing the questionnaire were not addressed. The English translation of the questionnaire is in Appendix A.

Apart from questions related to patients' characteristics, we surveyed their awareness about radiation exposure and risks, and their fear of the CT examination. Patients also indicated sources of their information and particular pieces of information they had obtained. Page 2 contained the Zung self-rating anxiety scale. ${ }^{10}$ Patients then read the information sheet about the $\mathrm{CT}$ examination, including the presence of X-rays and their potential to induce cancer in a small fraction of cases. The risks of contrast material administration (adverse reaction, renal impairment) were explained. The last page of the questionnaire surveyed the way in which the awareness of radiation exposure, risks of CT examination and patients' fear changed. Final questions related to the communication of the examination result.
Finally, a radiologist (LL) reviewed the examination report and marked those with adverse result (disease progression or a major complication).

Statistical evaluation was performed with SPSS v. 19 (IMB Corp., Armonk, USA) using Kendall's tau-b bivariate correlation $(\tau), X^{2}$ test and Mann-Whitney U test as appropriate. A p-value below 0.05 was considered significant.

\section{Results}

From 315 questionnaires, 263 (83\%) were returned completed. Most patients $(n=239,91 \%)$ had previously undergone at least $1 \mathrm{CT}$ examination. Patient characteristics are listed in Table 1.

Table 1. Patients' characteristics

\begin{tabular}{|l|c|}
\hline Patients, $n$ & 263 \\
\hline Age [years] & $62 \pm 12$ \\
\hline Gender (males) & $99(38 \%)$ \\
\hline Malignant condition & $237(90 \%)$ \\
\hline Education & \\
basic education & $45(17 \%)$ \\
high school & $118(45 \%)$ \\
higher education & $24(9 \%)$ \\
university & $76(29 \%)$ \\
\hline Number of previous CT examinations & $24(9 \%)$ \\
0 & $67(25 \%)$ \\
$1-2$ & $74(28 \%)$ \\
$3-4$ & $98(37 \%)$ \\
$\geq 5$ & \\
\hline Type of CT examination & $81(31 \%)$ \\
abdomen + pelvis & $182(69 \%)$ \\
thorax + abdomen + pelvis & \\
\hline Radiation exposure & $801 \pm 254$ \\
dose-length product (mGy·cm) & \\
\hline
\end{tabular}

In risk assessment, 25 (10\%) patients underestimated radiation exposure, 121 (46\%) underestimated the risk of developing a secondary tumor and 110 (42\%) underestimated the risk of renal impairment (Fig. 1). After reading the information, the patients generally corrected their evaluation of the risks of carcinogenesis and renal impairment but were more likely to overestimate radiation exposure. Males $(\tau=0.16, p=0.010)$ and older $(\tau=-0.11, p=0.029)$

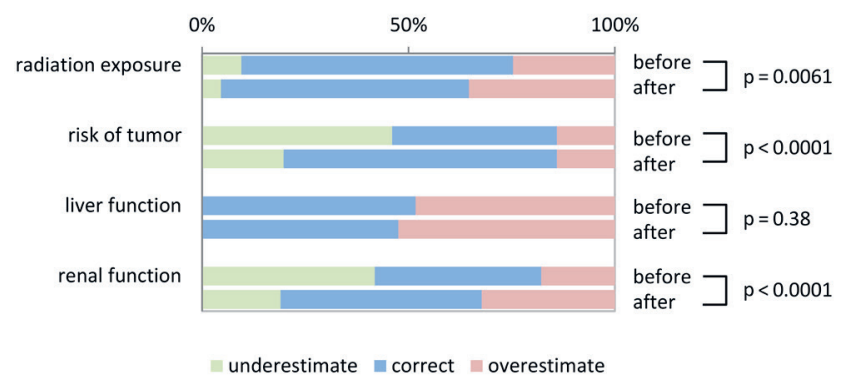

Fig. 1. Assessment of CT-related risks by patients undergoing CT examination before and after being given information about the examination 
Table 2. Patients' responses according to age, gender, education, and number of previous CTs expressed as Kendall's tau

\begin{tabular}{|c|c|c|c|c|c|c|c|c|}
\hline \multirow[t]{2}{*}{ Variable } & \multicolumn{2}{|c|}{$\begin{array}{l}\text { Age } \\
\text { years }\end{array}$} & \multicolumn{2}{|c|}{$\begin{array}{c}\text { Gender } \\
1=\text { female, } 2 \text { = male }\end{array}$} & \multicolumn{2}{|c|}{$\begin{array}{c}\text { Education } \\
1=\text { primary school, } \\
4=\text { university }\end{array}$} & \multicolumn{2}{|c|}{$\begin{array}{l}\text { Previous CTs } \\
\text { number }\end{array}$} \\
\hline & tau & $p$-value & tau & $p$-value & $\operatorname{tau}$ & $p$-value & tau & $p$-value \\
\hline \multicolumn{9}{|l|}{$\begin{array}{l}\text { Before reading the information } \\
\text { sheet ( } 1=\text { underestimate, } \\
2=\text { correct, } 3=\text { overestimate) }\end{array}$} \\
\hline radiation exposure & -0.120 & 0.012 & -0.147 & 0.011 & 0.069 & 0.212 & -0.036 & 0.481 \\
\hline tumor development & -0.108 & 0.029 & 0.156 & 0.010 & 0.042 & 0.464 & -0.207 & 0.000 \\
\hline liver impairment & -0.011 & 0.830 & 0.047 & 0.445 & 0.021 & 0.717 & -0.076 & 0.167 \\
\hline renal impairment & -0.001 & 0.988 & 0.040 & 0.499 & 0.038 & 0.505 & -0.114 & 0.033 \\
\hline \multicolumn{9}{|l|}{$\begin{array}{l}\text { Improvement of knowledge after } \\
\text { reading the information sheet } \\
\text { (improved =1, unchanged }=2 \text {, } \\
\text { worse }=3 \text { ) }\end{array}$} \\
\hline radiation exposure & -0.050 & 0.328 & -0.016 & 0.794 & -0.054 & 0.362 & -0.013 & 0.818 \\
\hline tumor development & -0.028 & 0.581 & 0.025 & 0.692 & -0.047 & 0.428 & -0.078 & 0.160 \\
\hline liver impairment & 0.108 & 0.040 & -0.074 & 0.246 & -0.121 & 0.051 & 0.057 & 0.325 \\
\hline renal impairment & 0.021 & 0.681 & 0.047 & 0.451 & 0.161 & 0.007 & -0.209 & 0.000 \\
\hline \multicolumn{9}{|l|}{$\begin{array}{l}\text { Fear }(1=\text { no fear, } 2=\text { little fear, } \\
3=\text { great fear })\end{array}$} \\
\hline fear from CT examination & -0.168 & 0.001 & 0.158 & 0.010 & 0.043 & 0.463 & -0.063 & 0.247 \\
\hline $\begin{array}{l}\text { fear from intravenous contrast } \\
\text { material }\end{array}$ & -0.089 & 0.079 & 0.111 & 0.071 & 0.044 & 0.452 & -0.047 & 0.389 \\
\hline fear from the examination result & -0.049 & 0.314 & 0.184 & 0.002 & -0.048 & 0.403 & -0.131 & 0.014 \\
\hline \multicolumn{9}{|l|}{$\begin{array}{l}\text { Fear change after reading } \\
\text { the information sheet (markedly } \\
\text { decreased }=1 \text {, no change }=3 \text {, } \\
\text { markedly increased }=5 \text { ) }\end{array}$} \\
\hline $\begin{array}{l}\text { change in fear from } \\
\text { the examination }\end{array}$ & -0.096 & 0.048 & -0.235 & 0.000 & 0.143 & 0.012 & 0.036 & 0.496 \\
\hline
\end{tabular}

patients and those who had had previous experience with CT examination ( $\mathrm{c}=-0.21, \mathrm{p}<0.0001)$ tended to underestimate the risks of radiation exposure more (Table 2 ). Patients who had previously undergone CT examinations underestimated the possible impact of contrast material on renal function more $(\tau=-0.11, \mathrm{p}=0.033)$. Reading the information sheet confused $6 \%$ to $18 \%$ of patients, depending on the question. The vast majority of patients ( $\mathrm{n}=227,86 \%)$ stated that they were not instructed to maintain fluid intake up to $1 \mathrm{~h}$ before the procedure.

Sources of patients' information are shown in Table 3. The most frequent source of information was the referring physician (67\% patients).

Patients feared the result of the examination more than the injection of contrast material or the examination itself ( $\mathrm{p}<0.0001$, Fig. 2). Fear of the CT examination was more pronounced in younger $(\tau=-0.22, \mathrm{p}=0.0003)$ and female patients $(\tau=-0.17, \mathrm{p}=0.0009)$. Patients who had previously undergone CT examinations feared the result of the examination less $(\tau=-0.17, \mathrm{p}<0.006)$. After reading the information sheet, 195 (74\%) patients reported experiencing greater fear of the examination $(\mathrm{p}<0.0001$, Fig. 2), in particular females $(\tau=-0.24, \mathrm{p}<0.0001)$, younger patients $(\tau=-0.096, p=0.0048)$ and those with a higher level of education $(\tau=0.143, p=0.012)$. Especially younger patients reported increased fear of the radiation exposure and contrast material administration $(\tau=-0.22$, $\mathrm{p}=0.0003 ; \mathrm{\tau}=-0.14, \mathrm{p}=0.025$, respectively). The majority

Table 3. Sources of patients' information and particular pieces of information they had obtained

\begin{tabular}{|l|c|c|}
\multicolumn{1}{|c|}{ Information } & Yes & No \\
\hline No food at least 5 h prior to CT & $251(95 \%)$ & $12(5 \%)$ \\
\hline Can drink up to 1 h prior to CT & $36(14 \%)$ & $227(86 \%)$ \\
\hline How CT examination proceeds & $87(33 \%)$ & $176(67 \%)$ \\
\hline Contrast agent & $144(55 \%)$ & $119(45 \%)$ \\
\hline Radiation burden & $50(19 \%)$ & $213(81 \%)$ \\
\hline Alternative to CT examination & $51(19 \%)$ & $212(81 \%)$ \\
\hline \multicolumn{1}{|c|}{ Information source } & yes & no \\
\hline Referring physician & $176(67 \%)$ & $87(33 \%)$ \\
\hline Previous examinations & $144(55 \%)$ & $119(45 \%)$ \\
\hline Internet & $21(8 \%)$ & $242(92 \%)$ \\
\hline Friends, relatives, other patients & $12(5 \%)$ & $251(95 \%)$ \\
\hline Radiology staff & $18(7 \%)$ & $245(93 \%)$ \\
\hline
\end{tabular}


Table 4. Patients' responses and preferences regarding the examination result

\begin{tabular}{|c|c|c|c|c|}
\hline Question & \multicolumn{4}{|c|}{ Response } \\
\hline \multirow{2}{*}{ I will know the result within } & 3 days & week & month & >month \\
\hline & $164(62 \%)$ & $76(29 \%)$ & $16(6 \%)$ & $6(2 \%)$ \\
\hline \multirow{2}{*}{ I will find out the result } & by phone & by post & by e-mail & by visiting the physician \\
\hline & 79 (30\%) & $0(0 \%)$ & $0(0 \%)$ & $184(70 \%)$ \\
\hline \multirow{2}{*}{ I wish to know the result within } & $1 \mathrm{~h}$ & 1 day & 3 days & 1 week \\
\hline & $61(23 \%)$ & $88(33 \%)$ & $30(11 \%)$ & $84(32 \%)$ \\
\hline \multirow{2}{*}{ Before I know the result, I will be } & comfortable & mildly uncomfortable & severely uncomfortable & \\
\hline & $58(22 \%)$ & $154(59 \%)$ & $50(19 \%)$ & \\
\hline
\end{tabular}

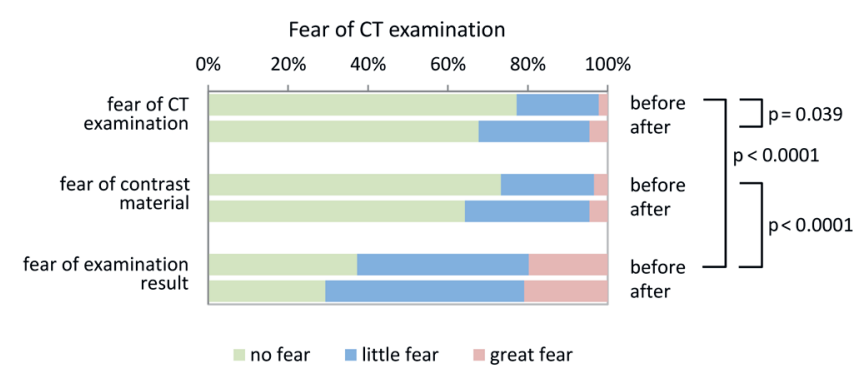

Fear change after reading the information about the examination

reported
fear change

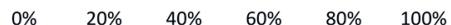

$\llbracket$ much lower $(0 \%) \rrbracket$ lower $(17 \%) \rrbracket$ same $(9 \%) \rrbracket$ greater $(66 \%) \backsim$ much greater $(8 \%)$

Fig. 2. Fear of $\mathrm{CT}$ examination before and after reading the information sheet

of patients (79\%) reported that they had learned new information or had refined their knowledge. None of the patients refused to undergo the examination based on the information presented in the questionnaire.

Mean anxiety score rated by the Zung self-rating anxiety scale was 34 points (interquartile range, 7 points), which is within the normal range (20-44 points). There was no correlation between the score and fear of the CT examination, contrast material administration or the result of the examination. Likewise, we found no correlation with fear reported after reading the information, or with the actual result of the examination (25\% patients had progression of the disease or a major complication).

Two-thirds of patients stated that they would receive the examination results from the referring physician within 3 days. Most patients admitted that they would be uncomfortable before they receive the result. One-quarter of the patients would like to know the result within $1 \mathrm{~h}$ (Table 4).

\section{Discussion}

The first part of this study showed that roughly half of the patients do not evaluate radiation exposure as well as other risks related to CT examination correctly. Patients fear the result of the examination more than the potential risks associated with the examination. Supplying this information results in a better appreciation of the risks, but also increases fear, especially in younger women with a higher level of education.

In this study, patients had better awareness of the radiation exposure with $66 \%$ being correct, compared to a study in emergency patients of a younger age conducted by Bauman et al. with $45 \%{ }^{6}$ or even less in other studies. ${ }^{3,11,12}$ On the other hand, $46 \%$ patients were not aware of the impact of radiation on human health. The risks were underestimated, especially by older male patients with previous CT examinations. Similarly to a study conducted by Singh et al., most participants were not educated about radiation exposure by their referring physician in any way. ${ }^{12}$ Our study showed that patients read and tried to comprehend information presented to them by the medical staff in print, which resulted in improved assessment of examination-related risks.

As shown in patients' response to questions about their fear, they believe correctly that the result of the examination has a larger influence on their health compared to risks related to it. The risk of having an adverse result of the CT examination ( $25 \%$ in our sample) is greater than the risk of a severe adverse reaction to non-ionic contrast material $(0.04 \%)$ or the risk of developing a secondary malignancy decades later (0.05\%). ${ }^{11,13,14}$ After reading the information, patients generally experience greater fear irrespective of their general anxiety level measured by the Zung selfrating anxiety scale. ${ }^{10}$ This effect is pronounced especially in younger women who had little experience with $\mathrm{CT}$ and therefore may require more counseling.

The information about the examination is primarily delivered by the referring physician $(67 \%$ of patients in this study), who has a bond of trust and who can provide the patient with an information letter. ${ }^{17,18}$ In a study conducted by Caoili et al., $47 \%$ of the respondents were educated about CT by their physicians, and $70 \%$ of them regarded this input as important. ${ }^{3}$ Although nearly all patients knew that they should abstain from food for $5 \mathrm{~h}$, only $14 \%$ were aware that soft drinks are allowed up to $1 \mathrm{~h}$ before the examination. This recommendation, which may decrease the risk of contrast-induced nephropathy, should also be pointed out to the physicians. ${ }^{14}$ 
Although information sheets may be distributed among patients (by the referring physicians) with the effect of improving their understanding of CT-related risks, they may lack cognitive reassurance delivered with empathy that would decrease their fear. ${ }^{15}$ We believe that when communicating radiation concerns, medical professionals should inform the patients about its presence and reassure them that subtle health risks may be dismissed in the view of a much greater benefit of exposing an important finding that may guide their further treatment.,16

Two-thirds of patients will receive examination results within 3 days, mostly when visiting the physician. In our experience, composing a report with a concise conclusion in a timely manner facilitates patient workflow in a clinical department and reduces the number of phone queries that interrupt work. Unfortunately, under normal circumstances, our department is unable to cope with $1 / 4$ of respondents requesting the report within 1 h. ${ }^{19}$ However, rapid communication of the examination result would make patients feel more comfortable and might be regarded as an extra service.

This study has the following limitations. It was performed in patients from a single center undergoing 1 particular type of CT examination. Selection of patients may have been affected by convenience sampling bias by not including those who would not cope with the questionnaire. Because of the paucity of similar studies, we were unable to comment on trends in patients' awareness, perception and attitude to contrast-enhanced CT examinations.

\section{Conclusions}

More than half of the patients do not evaluate radiation exposure and other risks related to CT examination correctly. Although information sheet improves patients' understanding of CT-related risks, it may lack empathetically delivered reassurance and increase fear especially in younger women with higher level of education and without previous experience with CT. Patients are primarily educated by their referring physicians who frequently fail to communicate important points. Patients generally fear the result of the examination more than potential risks associated with the examination. Most patients would be uncomfortable before they receive the examination result.

\section{References}

1. Adam EJ. Changes in the computed tomography patient population. Eur Radiol Suppl. 2006;16(4):D38-D42.

2. Lambert L, Foltan O, Briza J, et al. Growing number of emergency cranial CTs in patients with head injury not justified by their clinical need. Wien Klin Wochenschr. 2017;129(5-6):159-163.

3. Caoili EM, Cohan RH, Ellis JH, Dillman J, Schipper MJ, Francis IR. Medical decision making regarding computed tomographic radiation dose and associated risk: The patient's perspective. Arch Intern Med. 2009;169(11):1069-1081.

4. Raman SP, Johnson PT, Deshmukh S, Mahesh M, Grant KL, Fishman EK. CT dose reduction applications: Available tools on the latest generation of CT scanners. J Am Coll Radiol. 2013;10(1):37-41.

5. Lambert L, Ourednicek P, Briza J, et al. Sub-milliSievert ultralow-dose CT colonography with iterative model reconstruction technique. Peer J. 2016;4:e1883. doi:10.7717/peerj.1883

6. Baumann BM, Chen EH, Mills AM, et al. Patient perceptions of computed tomographic imaging and their understanding of radiation risk and exposure. Ann Emerg Med. 2011;58(1):1-7.e2.

7. Ramanathan $\mathrm{S}$, Ryan J. Radiation awareness among radiology residents, technologists, fellows and staff: Where do we stand? Insights Imaging. 2015;6(1):133-139.

8. Szarmach A, Piskunowicz M, Świętoń D, et al. Radiation safety awareness among medical staff. Pol J Radiol. 2015;80:57-61.

9. Boutis K, Cogollo W, Fischer J, Freedman SB, Ben David G, Thomas KE. Parental knowledge of potential cancer risks from exposure to computed tomography. Pediatrics. 2013;132(2):305-311.

10. Zung WW. A rating instrument for anxiety disorders. Psychosomatics. 1971;12(6):371-379.

11. Power SP, Moloney F, Twomey M, James K, O'Connor OJ, Maher MM. Computed tomography and patient risk: Facts, perceptions and uncertainties. World J Radiol. 2016;8(12):902-915.

12. Singh N, Mohacsy A, Connell DA, Schneider ME. A snapshot of patients' awareness of radiation dose and risks associated with medical imaging examinations at an Australian radiology clinic. Radiogr Lond Engl 1995. 2017;23(2):94-102.

13. Hricak H, Brenner DJ, Adelstein SJ, et al. Managing radiation use in medical imaging: A multifaceted challenge. Radiology. 2011;258(3): 889-905.

14. Dickinson MC, Kam PCA. Intravascular iodinated contrast media and the anaesthetist. Anaesthesia. 2008;63(6):626-634

15. Lin MP, Probst MA, Puskarich MA, et al. Improving perceptions of empathy in patients undergoing low-yield computerized tomographic imaging in the emergency department. Patient Educ Couns. 2017; 101(4):717-722.

16. Doss M. Linear no-threshold model may not be appropriate for estimating cancer risk from CT. Radiology. 2014;270(1):307-308.

17. Ukkola L, Oikarinen $\mathrm{H}$, Henner A, Honkanen $\mathrm{H}$, Haapea $\mathrm{M}$, Tervonen O. Information about radiation dose and risks in connection with radiological examinations: What patients would like to know. Eur Radiol. 2016;26(2):436-443.

18. Krille L, Hammer GP, Merzenich H, Zeeb H. Systematic review on physician's knowledge about radiation doses and radiation risks of computed tomography. Eur J Radiol. 2010;76(1):36-41.

19. Pahade J, Couto C, Davis R, Patel P, Siewert B, Rosen M. Reviewing imaging examination results immediately after study completion with a radiologist: Patient preferences and assessment of feasibility in an academic department. AJR Am J Roentgenol. 2012;199(4): 844-851. 


\section{Appendix A: Questionnaire}

\section{FIRST PAGE}

\begin{tabular}{|l|c|c|c|c|}
\hline 1. Gender & Female & Male & \\
\hline 2. Education & Basic school & High school & Higher education & University \\
\hline
\end{tabular}

\begin{tabular}{|l|l|l|l|l|l|l|}
\hline $\begin{array}{l}\text { 3. How many previous CT examinations } \\
\text { have you undergone? }\end{array}$ & 0 & 1 & 2 & 3 & 4 & more \\
\hline
\end{tabular}

What is the radiation exposure associated with CT examination?

\begin{tabular}{c|c|c} 
None & $\begin{array}{c}\text { Low } \\
\text { (eg. chest x-ray, } \\
\text { flight) }\end{array}$ & $\begin{array}{c}\text { Moderate } \\
\text { (eg. annual radiation } \\
\text { background) }\end{array}$
\end{tabular}

High

(eg. radiotherapy)

\begin{tabular}{|c|c|c|c|c|c|}
\hline \multicolumn{6}{|c|}{ What impact can your CT examination have on your health? } \\
\hline 5a. & Tumor development & No risk & Low risk & Moderate risk & High risk \\
\hline $5 \mathrm{~b}$. & Liver impairment & No risk & Low risk & Moderate risk & High risk \\
\hline $5 \mathrm{c}$. & Renal impairment & No risk & Low risk & Moderate risk & High risk \\
\hline
\end{tabular}

\begin{tabular}{|c|c|c|c|c|}
\hline 6. & From CT examination, I have & No fear & Little fear & Great fear \\
\hline 7. & From intravenous contrast material, I have & No fear & Little fear & Great fear \\
\hline 8. & From the examination result, I have & No fear & Little fear & Great fear \\
\hline
\end{tabular}

\begin{tabular}{|c|c|}
\hline Wha & formation about the CT examination were you given by the referring \\
\hline 9a. & I should abstain from food at least 5 hours prior to the examination \\
\hline $9 \mathrm{~b}$. & I can drink up to one hour prior to the CT examination \\
\hline $9 c$. & How CT examination proceeds \\
\hline $9 d$. & Contrast material administration \\
\hline 9e. & Radiation burden \\
\hline $9 f$. & Whether there is an alternative to the CT examination \\
\hline
\end{tabular}

\begin{tabular}{|c|}
\hline I have information about the CT examin \\
\hline 10a. the referring physician \\
\hline 10b. previous examinations \\
\hline 10c. the internet \\
\hline $10 \mathrm{~d}$. friends, relatives, other patients \\
\hline 10e. the radiology staff \\
\hline
\end{tabular}




\section{AFTER READING INFORMATION FOR PATIENTS}

\begin{tabular}{|l|l|l|l|}
\hline $\begin{array}{l}\text { 1. What is the radiation exposure } \\
\text { associated with CT examination? }\end{array}$ & None & $\begin{array}{c}\text { Low } \\
\text { (eg. chest X-ray, } \\
\text { flight) }\end{array}$ & $\begin{array}{c}\text { Moderate } \\
\text { (eg. annual radiation } \\
\text { background) }\end{array}$
\end{tabular}

What impact can your CT examination have on your health?

\begin{tabular}{|c|c|c|c|c|c|}
\hline $2 a$. & Tumor development & No risk & Low risk & Moderate risk & High risk \\
\hline $2 b$. & Liver impairment & No risk & Low risk & Moderate risk & High risk \\
\hline $2 \mathrm{c}$. & Renal impairment & No risk & Low risk & Moderate risk & High risk \\
\hline
\end{tabular}

\begin{tabular}{|c|c|c|c|c|}
\hline 3a. & From CT examination, I have & No fear & Little fear & Great fear \\
\hline $3 b$. & From intravenous contrast material, I have & No fear & Little fear & Great fear \\
\hline 3c. & From the examination result, I have & No fear & Little fear & Great fear \\
\hline
\end{tabular}

\begin{tabular}{|l|l|}
\hline After reading information about the examination \\
\hline 4a. I learned completely new information \\
\hline 4b. I updated my knowledge about the examination \\
\hline 4c. I learned nothing new \\
\hline 4d. I am still decided to undergo the examination \\
\hline
\end{tabular}

After reading information about the examination, my fear from the examination

\begin{tabular}{|l|l|l|l|l}
\hline $\begin{array}{l}\text { markedly } \\
\text { decreased }\end{array}$ & $\begin{array}{c}\text { somewhat } \\
\text { decreased }\end{array}$ & $\begin{array}{c}\text { did not } \\
\text { change }\end{array}$ & $\begin{array}{c}\text { somewhat } \\
\text { increased }\end{array}$ & $\begin{array}{l}\text { markedly } \\
\text { increased }\end{array}$ \\
\hline
\end{tabular}

\begin{tabular}{|c|c|c|c|c|}
\hline $6 a$. I will receive the examination result within & three days & $\begin{array}{c}\text { one } \\
\text { week }\end{array}$ & a month & $\begin{array}{l}\text { more than a } \\
\text { month }\end{array}$ \\
\hline $6 \mathrm{~b}$. I will receive the examination result & by phone & by post & by e-mail & $\begin{array}{l}\text { by visiting the } \\
\text { physician }\end{array}$ \\
\hline $6 \mathrm{c}$. I wish to know at least a preliminary result within & one hour & one day & three days & one week \\
\hline $\begin{array}{l}\text { Before I receive the examination } \\
\text { result, I will be }\end{array}$ & ortable & $\begin{array}{r}\text { milc } \\
\text { uncomf }\end{array}$ & $\begin{array}{l}\text { y } \\
\text { rtable }\end{array}$ & $\begin{array}{c}\text { severely } \\
\text { uncomfortable }\end{array}$ \\
\hline
\end{tabular}

